\title{
Home Visiting for Adolescent Mothers: Effects on Parenting, Maternal Life Course, and Primary Care Linkage
}

\author{
Beth Barnet, $M D^{1}$ \\ Jiexin Liu, PhD, MBA, MS \\ Margo DeVoe, $M S^{1}$ \\ Kari Alperovitz-Bichell, $M D, M P H^{1}$ \\ Anne K. Duggan, ScD ${ }^{2}$ \\ 'Department of Family Medicine, \\ University of Maryland School \\ of Medicine, Baltimore, Md \\ ${ }^{2}$ Department of Pediatrics, Johns \\ Hopkins University School \\ of Medicine, Baltimore, Md
}

\begin{abstract}
PURPOSE Adolescent mothers are at risk for rapidly becoming pregnant again and for depression, school dropout, and poor parenting. We evaluated the impact of a community-based home-visiting program on these outcomes and on linking the adolescents with primary care.

METHODS Pregnant adolescents aged 12 to 18 years, predominantly with low incomes and of African American race, were recruited from urban prenatal care sites and randomly assigned to home visiting or usual care. Trained home visitors, recruited from local communities, were paired with each adolescent and provided services through the child's second birthday. They delivered a parenting curriculum, encouraged contraceptive use, connected the teen with primary care, and promoted school continuation. Research assistants collected data via structured interviews at baseline and at 1 and 2 years of follow-up using validated instruments to measure parenting (Adult-Adolescent Parenting Inventory) and depression (Center for Epidemiologic Studies Depression). School status and repeat pregnancy were self-reported. We measured program impact over time with intention-to-treat analyses using generalized estimating equations (GEE).

RESULTS Of 122 eligible pregnant adolescents, 84 consented, completed baseline assessments, and were randomized to a home-visited group $(n=44)$ or a control group ( $n=40)$. Eighty-three percent completed year 1 or year 2 follow-up assessments, or both. With GEE, controlling for baseline differences, follow-up parenting scores for home-visited teens were 5.5 points higher than those for control teens (95\% confidence interval, 0.5-10.4 points; $P=.03$ ) and their adjusted odds of school continuation were 3.5 times greater (95\% confidence interval, 1.1-11.8; $P<.05)$. The program did not have any impact on repeat pregnancy, depression, or linkage with primary care.
\end{abstract}

CONCLUSIONS This community-based home-visiting program improved adolescent mothers' parenting attitudes and school continuation, but it did not reduce their odds of repeat pregnancy or depression or achieve coordination with primary care. Coordinated care may require explicit mechanisms to promote communication between the community program and primary care.

Ann Fam Med 2007;5:224-232. DOI: 10.1370/afm.629.

\section{INTRODUCTION}

dolescent mothers experience rapid repeat pregnancy in the short
term, ${ }_{1}^{1}$ depression, ${ }^{2}$ and school dropout,${ }^{3,4}$ as well as a reduced prob-
ability of future economic independence. ${ }^{5}$ Compared with their adult counterparts, teenage mothers may interact with their children less positively and have unrealistic expectations of child behavior that increase the risk of abuse and neglect. ${ }^{6,7}$ Adolescent mothers and children growing up in disadvantaged communities afflicted by drugs, violence, and inadequate supports may be particularly vulnerable. ${ }^{8}$ 
Family physicians provide most of the adolescent medical care in the United States ${ }^{9}$ but the typical office may find it challenging to address the multifaceted needs of pregnant and parenting teenagers. Primary care clinicians may be better positioned to address these issues if they work in concert with community-based programs. ${ }^{10}$

Home visiting is a community-based strategy for delivering services that aims to improve outcomes for high-risk families through education and support. ${ }^{11}$ It can function as a mechanism for integrating health and other services. ${ }^{12}$ For adolescents who are hard to engage, at high risk, and living under adverse conditions, home visiting may be particularly beneficial. ${ }^{13,14}$

Studies of home visiting have raised questions about its practical importance and cost-effectiveness. ${ }^{14,15} \mathrm{~A}$ recent meta-analysis of 60 programs found wide variation in the effect sizes for outcomes, many of which were quite small. ${ }^{15}$ These variations in impact may be due to differences in the target population studied, program goals, design and implementation, outcomes measured, and variables that are difficult to quantify, such as the "fit" between staff and program participants. ${ }^{15}$

Although teenagers might be a group for whom home visiting may be effective, ${ }^{14}$ whether and to what extent these programs succeed in coordination with primary care have not been well studied. Such linkages may play a role in outcomes that are influenced by primary care, such as depression and repeat pregnancy. ${ }^{16-18}$

In 2000, we received funding to implement a community-based home-visiting program for pregnant and parenting teenagers. We evaluated the program experimentally to determine its impact on parenting attitudes and beliefs, repeat pregnancy, maternal depression, and school continuation. We also examined the program's success in linking adolescents with primary care. We hypothesized that having a usual source of care would be associated with reduced rates of repeat pregnancy and maternal depression.

\section{METHODS}

\section{Participant Population}

Between February 2001 and January 2003, pregnant adolescents aged 12 to 18 years whose pregnancies were of least 24 weeks' gestation were recruited from 3 urban, university-affiliated prenatal care sites in Baltimore, Md. Two sites were family medicine sites, and 1 was an obstetrician-gynecologist site. Adolescents attending these clinics were predominantly African American and economically disadvantaged. This study was approved by the Institutional Review Board of the University of Maryland School of Medicine.

\section{Design}

Program staff identified eligible adolescents from computer scheduling databases and approached them during a prenatal care visit and explained to them the program and study. After informed consent was obtained from adolescents and their parents or guardians, adolescents completed baseline structured interviews administered by research staff and were randomly assigned to a home-visited group or a usual care control group.

\section{Home-Visiting Program}

In the home-visited group, adolescent mothers received home visitation, mentoring, and case management from 1 of 3 African American women who were recruited from communities served by the program. Home visitors were required to have a high school degree and experience related to health care, child development, or social work. They were selected for their empathetic qualities, ability to relate to teens and families, communication skills, and knowledge of the community.

Home visitation started in the third trimester and was planned to occur biweekly for the first year of the child's life and then monthly until the child's second birthday. Each home visitor was assigned a caseload of up to 15 adolescents visited biweekly and up to 10 adolescents visited monthly. They received 2 days of initial training in the use of the curriculum, followed by ongoing training in depression, contraception, substance use, and domestic violence.

We defined a home visit as an in-person contact between the home visitor and adolescent. Two thirds of contacts occurred in adolescents' homes, whereas the remainder occurred elsewhere in the community, often because of safety concerns related to drug trafficking in the home.

Home visitors were to deliver a parenting curriculum and an adolescent curriculum. The curricula were grounded in social cognitive theory and were developed by a child development psychologist and an anthropologist specifically for urban, African American adolescent mothers. ${ }^{19,20}$ The parenting curriculum sessions aimed to improve teens' understanding of child development, teach and model good parenting attitudes and skills, and promote appropriate health care use. If the adolescent mother gave consent, the home visitor attempted to engage the baby's father along with the mother in parenting sessions. The adolescent curriculum sessions provided skills-based, interactive instruction on safer sexual practices, prevention of repeat pregnancy, goal setting geared toward school completion, and training geared toward improving communication and negotiation with partners. 
Additionally, home visitors sought to identify depression, partner violence, and school dropout. Adolescents were asked about psychosocial stressors and distress. Their mental health was discussed in biweekly multidisciplinary staff meetings. If depression was identified as a potential concern, the teen was referred to the program's social worker for further evaluation and counseling, and to primary care and mental health services. Home visitors conducted ongoing assessment of the teen's school status and actively worked to promote school continuation or reengagement (eg, meeting with school officials, parents).

Finally, home visitors sought to connect adolescents with primary care for management of their contraceptive needs. Adolescents selected their primary care site, which was often different from their prenatal site, based on insurance requirements, location, and preference.

Home visitors completed standardized forms to measure how actual service delivery conformed to program standards (eg, completion of curriculum sessions, linkages).

\section{Baseline and Follow-up Data Collection}

Research staff blinded to the adolescents' group assignment conducted structured baseline interviews. The evaluation was separate from program activities; thus, individual-level data collected from research interviews (eg, standardized depression assessments) were not shared with program staff.

Outcome data were collected when the child turned 1 and 2 years old. We used instruments with established psychometric properties to measure parenting attitudes and beliefs, and depression. Contraceptive behaviors, sexual relationships, repeat pregnancies, school status, and relationship with the baby's father were measured at each follow-up assessment. At the year 2 follow-up interview, we asked adolescents whether they had a "regular personal doctor."21 Those responding "yes" were considered to be linked to primary care.

\section{Measures}

Parenting attitudes and beliefs were measured with Bavolek's Adult-Adolescent Parenting Inventory (AAPI), ${ }^{22}$ which was designed to identify negative parenting attitudes and child-rearing practices associated with a high risk of adverse outcomes for the child. To assess condom and contraceptive use, adolescents were asked how often during the past 12 months they used condoms. Response choices were "never," "sometimes," "most times," and "always." They were also presented with a list of possible contraceptive methods and asked whether they had used the method. We grouped condom use into "always" vs "not always" and contraceptives into hormonal types (eg, medroxyprogesterone acetate) vs nonhormonal types (eg, spermicide). Repeat pregnancy and birth were assessed by self-report.

Depressive symptoms were measured using the Center for Epidemiologic Studies Depression (CES-D) scale, $^{23}$ which contains 20 questions asking about symptoms experienced in the past week. Adolescents having a score of 21 points or higher were defined as having moderate to severe depressive symptoms. ${ }^{24}$ For school status, we used the adolescents' self-reports of whether they were in school, were not in school, or had graduated by the year 2 follow-up interview, and whether they returned to school if, at baseline, they had dropped out.

We assessed maternal demographics and covariates that have been shown to be associated with parenting outcomes, repeat pregnancy, and depression. 5,6,25,26 These variables included history of sexual abuse, exposure to domestic violence, and substance use.

\section{Analyses}

We used the intention-to-treat approach to analyze the effectiveness of the program. ${ }^{27}$ Regardless of the adolescents' level of program participation (including no home visits and early dropout), we measured outcomes according to their originally assigned group. This method helps maintain the benefits of randomization and minimizes bias when participant attrition is related to outcomes of interest.

We used the $\chi^{2}$ Fisher exact test and Student $t$ test to test for differences between the home-visited and control groups in baseline and follow-up measures. We controlled for baseline differences in the follow-up analyses. We checked for differential attrition both within and between the groups. There was no difference between groups in attrition, but we did observe greater loss to follow-up among adolescents reporting greater domestic violence $(P<.05)$ and a trend toward greater attrition for those who were depressed at baseline $(P=$ .09). We controlled for these associations in analyses.

Generalized estimating equations $(\mathrm{GEE})^{28}$ were used to examine the impact of the home-visiting program on changes in adolescent mothers' parenting attitudes and beliefs, contraceptive behaviors, repeat pregnancy, depressive symptoms, school continuation, and linkage to primary care, adjusting for baseline differences. We used GEE because it produces a summary estimate of the group effect averaged over the year 1 and year 2 follow-up assessments, taking into account the correlation of the repeated measurements. We examined using random effects modeling to adjust for within-person and home visitor-level correlations, but the findings were unchanged.

Studies of home visiting demonstrate that participants often have high rates of attrition and receive fewer services than specified by the program's protocol. ${ }^{11,29}$ 
Consequently, we assessed adolescents' total number of completed curriculum sessions and then determined whether they had a high level of exposure $(\geq 75 \%$ of planned sessions) vs a low level of exposure $(<75 \%$ of planned sessions). We repeated the GEE analyses comparing parenting scores of home-visited vs control adolescents, including exposure level in the model and controlling for significant baseline differences.

Finally, we examined whether program participants were more likely to report having a regular personal doctor and whether this variable was associated with contraceptive, repeat pregnancy, and depression outcomes.

We defined statistical significance as $P<.05$ and a statistical trend as $.05<P<.10$. Our sample size of 40 per group yielded a power of 0.80 to test for an effect size of
0.40 for continuous outcomes. Missing values accounted for less than $6 \%$ of all tested independent variables. Descriptive statistics and GEE models were computed with Stata 8.0 (Stata Corp, College Station, Tex).

\section{RESULTS}

We identified 122 eligible pregnant adolescents (Figure 1). Of these, 32 (26\%) declined to give informed consent and another $6(5 \%)$ did not complete a baseline assessment. Eighty-four teens were randomized to receive home visits $(\mathrm{n}=44)$ and usual care as a control $(\mathrm{n}=40)$. Among those randomized, follow-up assessments were completed at 1 year by 62 teens $(74 \%)$ and at 2 years by 63 teens (75\%). Seventy (83\%) completed either assessment, and $56(67 \%)$ completed both assessments.

\section{Figure 1. Participant flow through the study.}

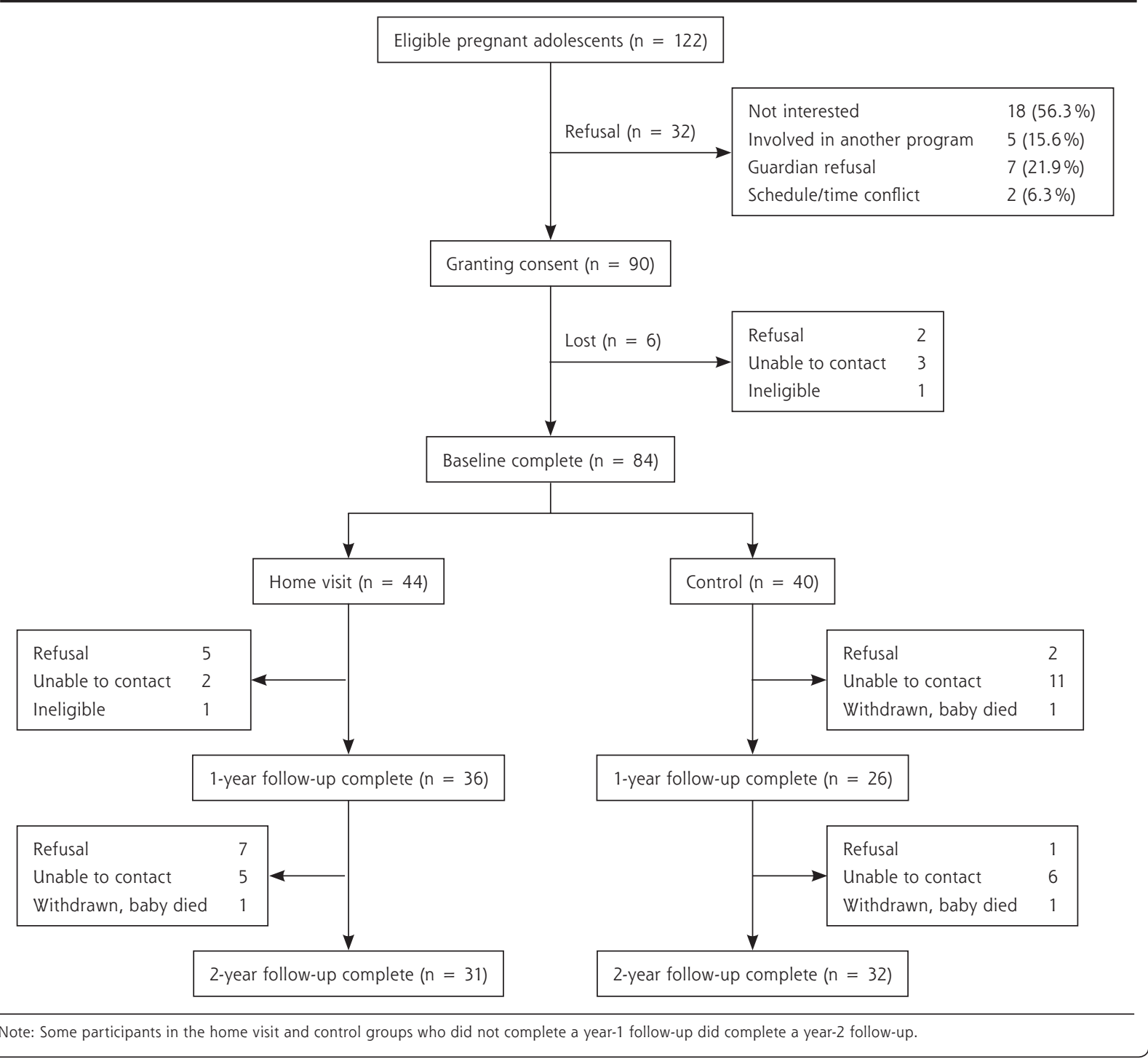




\section{Baseline Characteristics}

The home-visited and control groups were comparable on most measures at baseline, except that AAPI parenting scores were significantly higher in the home-visited group (Table 1 ). The population was predominantly African American, had low socioeconomic status, and experienced challenges and stressors including sexual abuse $(10 \%)$, physical fighting $(31 \%)$, depressive symptoms $(35 \%)$, and school dropout (30\%).

\section{Outcomes}

The program had a positive impact on adolescent mothers' parenting attitudes and beliefs. Compared with their control counterparts, home-visited adolescents had significantly improved changes over time in total AAPI scores and 2 of the subscales (Table 2).

Among the home-visited group, adolescents received fewer curriculum sessions than intended, 39\% in this group completed fewer than $75 \%$ of planned sessions. Home-visited teens who completed $75 \%$ or more of the parenting curriculum scored 8.3 points higher than control teens on the AAPI $(P<.005)$ (Table 3$)$. On average, high-exposure recipients were older (16.8 vs 15.8 years, $P<.05)$, but exposure level was not related to depression, domestic violence, or relationship with the baby's father.

We observed a trend toward greater consistent condom use among home-visited adolescents, but no impact on use of hormonal contraception, repeat pregnancy or birth, or depressive symptoms (Table 4). Thirty percent of teens had dropped out of school at baseline. Significantly more homevisited teens than control teens returned to school and graduated by 2 years postpartum (71\% vs $44 \%, P<.05)$.

At the year 2 follow-up interview, $61 \%$ of home-visited adolescents vs $44 \%$ of control adolescents reported having a regular personal doctor $(P$ $=.25$ ) (Table 5). Teens who reported having a personal doctor were younger and more likely to be depressed at the year 2 follow-up interview. Controlling for age, baseline depressive symptoms, and domestic violence, having a personal doctor was associated with depressive symptoms at the 2-year assessment (adjusted odds ratio $=3.9 ; 95 \%$ confidence interval, $0.9-17.9 ; P=.08)$ and continuous insurance (adjusted odds ratio $=4.5 ; 95 \%$ confidence interval, $1.0-20.9 ; P=.06)$, but not with program participation.

\section{DISCUSSION}

Our paraprofessional homevisiting program significantly improved adolescent mothers' parenting attitudes and beliefs 


\begin{tabular}{|c|c|c|c|c|c|c|}
\hline \multirow[b]{2}{*}{ Parenting Measure } & \multirow[b]{2}{*}{ Group } & \multicolumn{2}{|c|}{$\begin{array}{l}\text { Mean Score (SD)* } \\
\text { by Year of Follow-up }\end{array}$} & \multicolumn{3}{|c|}{$\begin{array}{c}\text { Difference in Score Change } \\
\text { Home Visit vs Control }\end{array}$} \\
\hline & & $\begin{array}{l}\text { Year } 1 \\
(n=62)\end{array}$ & $\begin{array}{l}\text { Year } 2 \\
(n=63)\end{array}$ & $\beta^{\ddagger}$ & $95 \% \mathrm{Cl}$ & $P$ Value \\
\hline \multirow[t]{2}{*}{ Total AAPI score, mean (SD) } & Home visit & $119.6(14.6)$ & $122.0(17.2)$ & 5.5 & 0.5 to 10.4 & .03 \\
\hline & Control & $110.1(13.7)$ & $111.8(14.7)$ & & & \\
\hline \multicolumn{7}{|l|}{ AAPI subscale scores, mean (SD) } \\
\hline \multirow[t]{2}{*}{ Appropriate expectations } & Home visit & $24.4(2.8)$ & $24.9(3.3)$ & 1.1 & 0.1 to 2.1 & .02 \\
\hline & Control & $23.0(2.3)$ & $23.3(2.4)$ & & & \\
\hline \multirow[t]{2}{*}{ Empathy } & Home visit & $29.2(4.3)$ & $30.9(4.2)$ & 1.7 & 0.3 to 3.4 & $<.05$ \\
\hline & Control & $27.0(4.3)$ & $27.5(4.8)$ & & & \\
\hline \multirow[t]{2}{*}{ Avoidance of physical punishment } & Home visit & $37.3(5.2)$ & $36.8(6.9)$ & 1.8 & -0.4 to 4.0 & .10 \\
\hline & Control & $34.7(6.1)$ & $34.2(5.7)$ & & & \\
\hline \multirow[t]{2}{*}{ Avoidance of role reversal } & Home visit & $28.6(6.5)$ & $29.4(7.7)$ & 1.3 & -1.1 to 3.7 & .28 \\
\hline & Control & $25.4(5.4)$ & $26.7(6.4)$ & & & \\
\hline
\end{tabular}

Table 3. Effect of Level of Exposure to the Parenting Curriculum on Adolescent Mothers' Parenting Attitudes and Beliefs

\begin{tabular}{|c|c|c|c|c|c|c|}
\hline \multirow[b]{3}{*}{ Parenting Measure } & \multicolumn{6}{|c|}{ Level of Exposure to Parenting Curriculum } \\
\hline & \multicolumn{3}{|c|}{$\begin{array}{c}\text { Low Exposure } \\
\text { ( }<75 \% \text { of Planned Sessions) }\end{array}$} & \multicolumn{3}{|c|}{$\begin{array}{c}\text { High Exposure } \\
\text { ( } \geq 75 \% \text { of Planned Sessions) }\end{array}$} \\
\hline & $\beta^{*}$ & $95 \% \mathrm{Cl}$ & $\begin{array}{c}P \\
\text { Value }\end{array}$ & $\beta^{*}$ & $95 \% \mathrm{Cl}$ & $\begin{array}{c}P \\
\text { Value }\end{array}$ \\
\hline Total AAPI score & 0.2 & -7.0 to 7.3 & .97 & 8.3 & 3.2 to 13.3 & $<.005$ \\
\hline \multicolumn{7}{|l|}{ AAPI subscale scores } \\
\hline Inappropriate expectations & 0.3 & -1.3 to 1.9 & .08 & 1.5 & 0.4 to 2.5 & .01 \\
\hline Empathy & 1.4 & -0.7 to 3.5 & .19 & 2.6 & 0.9 to 4.3 & $<.005$ \\
\hline $\begin{array}{l}\text { Avoidance of physical } \\
\text { punishment }\end{array}$ & 0.04 & -3.2 to 3.3 & .98 & 2.6 & 0.2 to 5.0 & .03 \\
\hline Avoidance of role reversal & -0.9 & -4.9 to 3.0 & .63 & 2.1 & -0.1 to 4.4 & .06 \\
\hline \multicolumn{7}{|c|}{ AAPI = Adult -Adolescent Parenting Inventory; $\mathrm{Cl}=$ confidence interval. } \\
\hline \multicolumn{7}{|c|}{$\begin{array}{l}\text { * } \beta=\text { the mean difference in score between intervention home-visited adolescents (with high or low exposure to } \\
\text { the curriculum) and control adolescents, using the generalized estimating equation (GEE), and adjusting for age, } \\
\text { baseline AAPI scores, baseline depressive symptoms, and household violence. }\end{array}$} \\
\hline
\end{tabular}

have been due to our sample's younger mean age and our use of a previously evaluated parenting curriculum that was culturally and age appropriate. ${ }^{25}$ We furthermore emphasized staff training and monitoring to ensure that staff acquired and used skills to teach, promote, and model positive parenting faithfully. ${ }^{20}$

Similar to programs that specifically target teenage mothers, ${ }_{1}^{15}$ our program significantly influenced school reentry and graduation. This effect may have been due to the home visitors' consistent and increased school continuation relative to usual care; however, the program was not effective in reducing the odds of repeat pregnancy or maternal depressive symptoms. We aimed to link teens with primary care and did observe a nonsignificant trend toward this outcome.

In contrast to findings from a meta-analysis of homevisiting programs that found small changes in parenting ${ }_{1}^{15}$ our findings found medium to large effect sizes on parenting outcomes. ${ }^{30}$ Specifically, among home-visited teens overall, the standardized effect size for improved parenting attitudes was 0.49 and was even higher, 0.72 , among adolescents who had a high level of exposure to the curriculum. These effect sizes are larger than that reported by Olds et al (effect size, 0.38$)^{31}$ and may messages and case management activities delivered in the context of their ongoing relationship with the teen. Disruptions in these relationships were rare; during the program's 4 -year lifetime, only 1 of the 3 home visitors left the program. Such continuity may enhance a trusting relationship and increase the impact of messages. ${ }^{32}$

On the other hand, this program did not improve use of hormonal contraception or reduce repeat pregnancy. Prior studies of home visitation have found a similar lack of impact on prevention of additional pregnancies. ${ }^{16,31} \mathrm{~A}$ possible explanation derives from research showing that knowledge of and access to contraceptive services alone do not reduce repeat pregnancy. ${ }^{33,34}$ Motivation to avoid pregnancy is influenced by many factors, including 
Table 4. Program Impact on Contraceptive and Pregnancy Outcomes, Mental Health, School Completion, and Linkage With Primary Care

\begin{tabular}{|c|c|c|c|c|c|c|}
\hline \multirow[b]{2}{*}{ Measure } & \multirow[b]{2}{*}{ Group } & \multicolumn{2}{|c|}{ Year of Follow-up } & \multicolumn{3}{|c|}{ Program Impact at 2 Years } \\
\hline & & $\begin{array}{l}\text { Year } 1 \\
\text { n (\%) }\end{array}$ & $\begin{array}{l}\text { Year } 2 \\
\text { n (\%) }\end{array}$ & AOR* & $95 \% \mathrm{Cl}$ & $P$ Value \\
\hline \multicolumn{7}{|l|}{ Contraceptive use and pregnancy outcomes } \\
\hline \multirow[t]{2}{*}{ Used condoms "always" in past 12 months } & Home visit & $18 / 36(50)$ & $17 / 31(55)$ & 3.6 & $0.9-14.4$ & .07 \\
\hline & Control & $9 / 26(35)$ & $12 / 32(38)$ & & & \\
\hline \multirow{2}{*}{$\begin{array}{l}\text { Used hormonal contraception in past } \\
12 \text { months }\end{array}$} & Home visit & $18 / 36(50)$ & $18 / 31(58)$ & 0.7 & $0.2-1.9$ & .46 \\
\hline & Control & $15 / 26(58)$ & $21 / 32(66)$ & 1.0 & & \\
\hline \multirow[t]{2}{*}{ Repeat pregnancy } & Home visit & $7 / 36(19)$ & $14 / 31(45)$ & 1.2 & $0.4-3.5$ & .69 \\
\hline & Control & $5 / 26(19)$ & $12 / 32(38)$ & 1.0 & & \\
\hline \multirow[t]{2}{*}{ Repeat birth } & Home visit & $3 / 36(8)$ & $4 / 31(13)$ & 0.6 & $0.2-2.6$ & .54 \\
\hline & Control & $2 / 26(8)$ & $6 / 32(19)$ & 1.0 & & \\
\hline \multicolumn{7}{|l|}{ Maternal mental health } \\
\hline \multirow[t]{2}{*}{ Depressive symptoms (CES-D score $\geq 21$ ) } & Home visit & $8 / 36(22)$ & $11 / 31(36)$ & 2.1 & $0.6-7.1$ & .24 \\
\hline & Control & $6 / 26(23)$ & $8 / 32(25)$ & 1.0 & & \\
\hline \multicolumn{7}{|l|}{ School status } \\
\hline \multirow[t]{2}{*}{ In school or graduated at year $2^{+}$} & Home visit & - & $22 / 31(71)$ & 3.5 & $1.1-11.8$ & $<.05$ \\
\hline & Control & - & $14 / 32(44)$ & 1.0 & & \\
\hline \multicolumn{7}{|l|}{ Linkage with primary care } \\
\hline \multirow[t]{2}{*}{ Has a regular personal doctor at year 2} & Home visit & - & $19 / 31(61)$ & 1.9 & $0.7-5.6$ & .23 \\
\hline & Control & _- & $15 / 32(47)$ & 1.0 & & \\
\hline
\end{tabular}

Table 5. Selected Characteristics of Adolescent Mothers With and Without a Regular Personal Doctor

\begin{tabular}{|c|c|c|c|}
\hline \multirow[b]{2}{*}{ Characteristic } & \multicolumn{2}{|c|}{$\begin{array}{c}\text { Adolescent Has a } \\
\text { Regular Personal Doctor }\end{array}$} & \multirow[b]{2}{*}{$\begin{array}{c}P \\
\text { Valu }\end{array}$} \\
\hline & $\begin{array}{c}\text { Yes } \\
(n=34)\end{array}$ & $\begin{array}{c}\text { No } \\
(n=29)\end{array}$ & \\
\hline \multicolumn{4}{|l|}{ Demographics } \\
\hline Age at baseline, mean (SD), y & $16.2(1.5)$ & $16.9(1.4)$ & .04 \\
\hline Lives with mother at year $2, \%$ & 62 & 46 & .23 \\
\hline Household conflict at year 2: CTS score, mean (SD) & $17.4(14.5)$ & $23.6(14.5)$ & .13 \\
\hline Continuous health insurance from baseline to year $2, \%$ & 42 & 26 & .19 \\
\hline \multicolumn{4}{|l|}{ Contraceptive use and pregnancy outcomes } \\
\hline Used condoms "always" in past 12 months at year 2, \% & 56 & 35 & .09 \\
\hline $\begin{array}{l}\text { Used hormonal contraception in past } 12 \text { months } \\
\text { at year } 2, \%\end{array}$ & 62 & 62 & .98 \\
\hline Repeat pregnancy by year $2, \%$ & 47 & 35 & .48 \\
\hline Repeat birth by year $2, \%$ & 18 & 14 & .68 \\
\hline \multicolumn{4}{|l|}{ Maternal mental health } \\
\hline $\begin{array}{l}\text { Depressive symptoms (CES-D score > 21) } \\
\text { at baseline, }{ }^{*} \%\end{array}$ & 38 & 21 & .13 \\
\hline $\begin{array}{l}\text { Depressive symptoms (CES-D score > } 21 \text { ) } \\
\text { at year } 2,+\%\end{array}$ & 41 & 17 & $<.05$ \\
\hline \multicolumn{4}{|l|}{ Group } \\
\hline Home visit & 61 & 39 & .25 \\
\hline Control & 47 & 53 & \\
\hline
\end{tabular}

partner preferences for having more children. ${ }^{35-37}$ Although our program did provide adolescents with contraceptive information and counseling, and taught them about safer sexual practices and negotiation skills, it lacked an explicit mechanism to address motivation as the key to postponing childbearing. ${ }^{35,38,39}$ Additionally, the program lacked specified methods to share information between the home visitors and the primary care physician. Studies suggest that defined communication protocols may facilitate a more seamless and integrated care process. ${ }^{40}$

Despite the program's focus on assessing adolescents for depression at baseline, providing therapy to those with depression, and recommending further treatment in primary care and mental health settings, the program did not 
have any impact on adolescent mothers' depressive symptoms. One possible explanation is that the program did not train the home visitors to use a standardized depression screening tool for ongoing assessment. Consequently, the program may have failed to identify adolescent mothers with incident depression between delivery and 2 years. ${ }^{2}$ Beyond this factor, merely identifying depression without giving adolescents specific evidence-based treatment does not improve outcomes. ${ }^{41}$ Even if depressed teens were referred to their primary care doctor, the program lacked a well-developed system to coordinate information between the home visitor and the teen's physician. Consequently, when the teen visited the physician, the physician may have failed to recognize her depression. ${ }^{42,43}$ Barriers in access to care are also likely to have played a part. During their pregnancy, more than $75 \%$ of the teenagers were covered by insurance (predominantly Medicaid), but fewer than $35 \%$ reported continuous insurance coverage during the 2 -year study period. Although speculative, our experience suggests that complicated welfare reform policies may contribute to loss of coverage after delivery. ${ }^{44}$

Multiple studies have shown that using care managers to complement the primary care physicians' role in the treatment of depression improves outcomes and is costeffective. ${ }^{45-47}$ It is possible that appropriately trained home visitors could serve such a role. Although our program aimed to coordinate care, our lack of adequate explicit mechanisms to communicate with the primary care clinician was a missed opportunity for bidirectional flow of information that might reinforce each setting's messages. ${ }^{48}$

This study raises questions about how to integrate community-based and primary care services for vulnerable teenage mothers. Studies have found that even within a single system of clinicians, communication is difficult ${ }^{49}$ and may be impractical, time-consuming, and economically unproductive for many clinicians. ${ }^{50}$ We believe that future trials should explore innovative methods for communicating important information (eg, the presence of depressive symptoms) between primary care clinicians and community programs. Successful linkages that promote and reinforce positive behavior change could prove more fruitful.

A major limitation of this study is its small sample

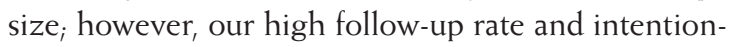
to-treat analysis strengthen our findings of a positive program impact on parenting attitudes and school continuation for this group. Second, although we used a randomized design, our study groups were not balanced at baseline on our main parenting measure, the AAPI score. It is also possible that our parenting outcome findings might have been different had we measured parenting through direct observation rather than self-report. Finally, we did not assess the content of primary care received by these teens. Consequently, we are unable to determine whether primary care clinicians provided appropriate contraceptive services or recognized and treated depression in these adolescent mothers.

In recent years, federal dollars have been drastically reduced for programs that support services for vulnerable pregnant and parenting teenagers in favor of ineffective programs that support "abstinence only until marriage." ${ }^{151,52}$ This trial reinforces prior studies showing the effectiveness of home visitation in improving important outcomes for economically disadvantaged adolescent mothers, and may be helpful in formulating evidencebased policy. It is possible that other important outcomes, such as repeat pregnancy and depression, could be altered with greater coordination of care. Community-based home-visiting programs and primary care practices may achieve greater benefits if they work together to develop and test explicit mechanisms and implementation systems that coordinate care for high-risk adolescents.

To read or post commentaries in response to this article, see it online at http://www.annfammed.org/cgi/content/full/5/3/224.

Key words: Pregnancy in adolescence; parenting; risk reduction behavior; community services; randomized controlled trials; integration; primary care; health promotion; vulnerable populations; minority groups; home visits; health care delivery; health services research

Submitted March 23, 2006; submitted, revised, June 8, 2006; accepted August 14, 2006.

This work was presented in part at the 31st Annual Meeting of the North American Primary Care Research Group, October 2003, Banff, Alberta.

Funding support: This work was supported by the Office of Adolescent Pregnancy Programs, Department of Health and Human Services, grant APHPA0002011. The principal investigator had full access to all the data in the study and takes responsibility for the integrity of the data and the accuracy of the data analysis.

\section{References}

1. Klerman L. Another Chance: Preventing Additional Births to Teen Mothers. Washington, DC: National Campaign to Prevent Teen Pregnancy; 2004.

2. Barnet B, Joffe A, Duggan AK, Wilson MD, Repke JT. Depressive symptoms, stress, and social support in pregnant and postpartum adolescents. Arch Pediatr Adolesc Med. 1996;150(1):64-69.

3. Leadbeater BJ. School outcomes for minority-group adolescent mothers at 28 to 36 months postpartum: a longitudinal follow-up. J Res Adolesc. 1996;6(4):629-648.

4. Barnet B, Arroyo C, Devoe M, Duggan AK. Reduced school dropout rates among adolescent mothers receiving school-based prenatal care. Arch Pediatr Adolesc Med. 2004;158(3):262-268.

5. Coley RL, Chase-Lansdale PL. Adolescent pregnancy and parenthood. Recent evidence and future directions. Am Psychol. 1998;53(2):152-166.

6. Eamon MK. Antecedents and socioemotional consequences of physical punishment on children in two-parent families. Child Abuse Negl. 2001;25(6):787-802.

7. Terry-Humen E, Manlove J, Moore K. Playing Catch-Up: How the Children of Teen Mothers Fare. Washington, DC: National Campaign to Prevent Teen Pregnancy; 2005. 
8. Garbarino J. Raising Children in a Socially Toxic Environment. San Francisco, Calif: Jossey-Bass; 1995.

9. Ma J, Wang Y, Stafford RS. U.S. adolescents receive suboptimal preventive counseling during ambulatory care. J Adolesc Health. 2005;36(5):441.

10. Woolf SH, Glasgow RE, Krist A, et al. Putting it together: finding success in behavior change through integration of services. Ann Fam Med. 2005;3(Suppl 2):S20-S27.

11. Gomby DS, Culross PL, Behrman RE. Home visiting: recent program evaluations-analysis and recommendations. Future Child. 1999;9(1):4-26, 195-223.

12. The role of home-visitation programs in improving health outcomes for children and families. American Academy of Pediatrics. Council on Child and Adolescent Health. Pediatrics. 1998;101(3 Pt 1):486489.

13. Hahn RA, Bilukha OO, Crosby A, et al. First reports evaluating the effectiveness of strategies for preventing violence: early childhood home visitation. Findings from the Task Force on Community Preventive Services. MMWR Recomm Rep. 2003;52(RR-14):1-9.

14. Karoly L, Greenwood PE. Investing in Our Children: What We Know and Don't Know About the Costs and Benefits of Early Childhood Intervention. Santa Monica, Calif: RAND; 1998.

15. Sweet MA, Appelbaum MI. Is home visiting an effective strategy? A meta-analytic review of home visiting programs for families with young children. Child Dev. 2004;75(5):1435-1456

16. El-Kamary SS, Higman SM, Fuddy L, et al. Hawaii's Healthy Start home visiting program: determinants and impact of rapid repeat birth. Pediatrics. 2004;114(3):e317-e326.

17. Stevens-Simon C, Nelligan D, Kelly L. Adolescents at risk for mistreating their children. Part II: A home- and clinic-based prevention program. Child Abuse Negl. 2001;25(6):753-769.

18. Leathers SJ, Kelley MA. Unintended pregnancy and depressive symptoms among first-time mothers and fathers. Am J Orthopsychia try. 2000;70(4):523-531.

19. Bronfenbrenner U. Ecological systems theory. In: Wozniak R, Fisher $\mathrm{K}$, eds. Specific Environments: Thinking in Contexts. Hillsdale, NJ: Erlbaum; 1993:3.

20. Black MM, Siegel EH, Abel Y, Bentley ME. Home and videotape intervention delays early complementary feeding among adolescent mothers. Pediatrics. 2001;107(5):E67.

21. Safran DG, Kosinski M, Tarlov AR, et al. The Primary Care Assessment Survey: tests of data quality and measurement performance. Med Care. 1998;36(5):728-739.

22. Bavolek S. Adult-Adolescent Parenting Inventory (AAPI). In: Touliatos J, Perlmutter B, Straus M, eds. Handbook of Family Measurement Techniques. Thousand Oaks, Calif: Sage Publications, Inc; 2001.

23. Radloff L. The CES-D scale: a self-report depression scale for research in the general population. Appl Psychol Meas. 1977;1:385-401.

24. Devins G, Orme C. Center for Epidemiologic Studies Depression scale. In: Keiser D, Sweetland R, eds. Test Critiques. Kansas City, Mo: Pro-Ed; 1985:144-160

25. Cicchetti D, Rizley R. Developmental perspectives on the etiology, intergenerational transmission and sequelae of child maltreatment. In: Cicchetti D, Rizley R, eds. New Directions for Child Development. San Francisco, Calif: Jossey-Bass; 1981;11:31-55.

26. Straus M. Manual for the Conflict Tactics Scales (CTS) and Test Forms for the Revised Conflict Tactics Scale (CTS2). Durham, NH: University of New Hampshire Family Research Laboratory; 1995.

27. McKinlay SM, Stone EJ, Zucker DM. Research design and analysis issues. Health Educ Q. 1989;16(2):307-313.

28. Diggle P, Heagerty P, Liang K, Zeger S. Analysis of Longitudinal Data. 2nd ed. New York, NY: Oxford University Press; 2002.

29. Duggan A, Windham A, McFarlane $E$, et al. Hawaii's Healthy Start Program of home visiting for at-risk families: evaluation of family identification, family engagement, and service delivery. Pediatrics. 2000;105(1 Pt 3):250-259.
30. Cohen J. Statistical Power Analysis for the Behavioral Sciences. 2nd ed. Hillsdale, NJ: Lawrence Erlbaum; 1988.

31. Olds DL, Robinson J, Pettitt L, et al. Effects of home visits by paraprofessionals and by nurses: age 4 follow-up results of a randomized trial. Pediatrics. 2004;114(6):1560-1568.

32. Jack SM, DiCenso A, Lohfeld L. A theory of maternal engagement with public health nurses and family visitors. J Adv Nurs. 2005;49(2):182-190.

33. Miller WB. Why some women fail to use their contraceptive method: a psychological investigation. Fam Plann Perspect. 1986;18(1):27-32.

34. Stevens-Simon C, Kelly L, Singer D, Nelligan D. Reasons for first teen pregnancies predict the rate of subsequent teen conceptions. Pediatrics. 1998;101(1):E8.

35. DiClemente RJ. The psychological basis of health promotion for adolescents. Adolesc Med. 1999;10(1):13-22, v.

36. Ruch-Ross HS, Jones ED, Musick JS. Comparing outcomes in a statewide program for adolescent mothers with outcomes in a national sample. Fam Plann Perspect. 1992;24(2):66-71, 96.

37. Maynard R, Rangarajan A. Contraceptive use and repeat pregnancies among welfare dependent teenage mothers. Fam Plann Perspect. 1994;26:198-205.

38. Britt $E$, Hudson SM, Blampied NM. Motivational interviewing in health settings: a review. Patient Educ Couns. 2004;53(2):147-155.

39. Petersen R, Payne P, Albright J, et al. Applying motivational interviewing to contraceptive counseling: ESP for clinicians. Contraception. 2004;69(3):213-217.

40. Stille CJ, Jerant A, Bell D, Meltzer D, Elmore JG. Coordinating care across diseases, settings, and clinicians: a key role for the generalist in practice. Ann Intern Med. 2005;142(8):700-708.

41. Tiemens BG, Ormel J, Simon GE. Occurrence, recognition, and outcome of psychological disorders in primary care. Am J Psychiatry. 1996;153(5):636-644.

42. Docherty JP. Barriers to the diagnosis of depression in primary care. J Clin Psychiatry. 1997;58(Suppl 1):5-10.

43. Borowsky SJ, Rubenstein LV, Meredith LS, et al. Who is at risk of nondetection of mental health problems in primary care? J Gen Intern Med. 2000;15(6):381-388.

44. The Henry J. Kaiser Family Foundation. Teens and TANF: How Adolescents Fare under the Nation's Welfare Program. December 2003. Available at: http://www.kff.org/womenshealth/3390-index.cfm. Accessed 3 June 2006

45. Hunkeler EM, Meresman JF, Hargreaves WA, et al. Efficacy of nurse telehealth care and peer support in augmenting treatment of depression in primary care. Arch Fam Med. 2000;9(8):700-708.

46. Simon GE, VonKorff M, Rutter C, Wagner E. Randomised trial of monitoring, feedback, and management of care by telephone to improve treatment of depression in primary care. BMJ. 2000;320(7234):550-554.

47. Dickinson LM, Rost K, Nutting PA, et al. RCT of a care manager intervention for major depression in primary care: 2-year costs for patients with physical vs psychological complaints. Ann Fam Med. 2005;3(1):15-22.

48. Duggan AK, McFarlane EC, Windham AM, et al. Evaluation of Hawaii's Healthy Start Program. Future Child. 1999;9(1):66-90; discussion 177-178.

49. Gandhi TK, Sittig DF, Franklin M, et al. Communication breakdown in the outpatient referral process. J Gen Intern Med. 2000;15(9):626-631.

50. Weiner SJ, Barnet B, Cheng TL, Daaleman TP. Processes for effective communication in primary care. Ann Intern Med. 2005;142(8):709714.

51. Dailard C. Abstinence promotion and teen family planning: the misguided drive for equal funding. The Guttmacher Report on Public Policy. 2002;5:1-3.

52. Santelli J, Ott MA, Lyon M, Rogers J, Summers D. Abstinence-only education policies and programs: a position paper of the Society for Adolescent Medicine. J Adolesc Health. 2006;38(1):83-87. 